\title{
Study of Inventory Management in Pharmaceuticals: A Review of COVID-19 Situation
}

\author{
Mir Mohammed Junaid Basha \\ Student \\ Industrial Engg. \& Mgmt. \\ RVCE, Bengaluru, India \\ Sonali Tukaram Wani \\ Student \\ Industrial Engg. \& Mgmt. \\ RVCE, Bengaluru, India
}

\author{
Navya V.S \\ Student \\ Industrial Engg. \& Mgmt. \\ RVCE, Bengaluru, India \\ Prof. Vivekanand S Gogi \\ Asst. Professor, Dept of \\ Industrial Engg. \& Mgmt. \\ RVCE, Bengaluru, India
}

\begin{abstract}
The study uses the inventory audit procedure to improve the inventory status of pharmaceuticals by selective inventory control techniques. Pharmaceuticals are vital sectors of medical industry, but because of the current situation, of COVID-19 Pandemic, there is a lot of reduction in capsule production, many of the pharmaceutical industries have rejected orders due to shortage of medicinal products during lockdown. This study uses systematic evaluation, statistical methods, Fuzzy logic, ABC-VED, EOQ, JIT etc. based on these methods the classification of various models for pharmaceutical inventory are incorporated. This also summarizes some of the case studies conducted based on the annual expenditure with $\mathrm{ABC}$ classification in the pharmaceuticals. The basic aim is to identify and improve the problems of inventory management by proposing a timely correct analysis. In this study, all methods that are primarily used in the inventory management of drug handling are reviewed and the best methods have been suggested that, when combined and applied in an automated environment, they can help to keep the inventory at an optimum level.
\end{abstract}

Keywords:- Inventory Management, Pharmaceuticals, ABC-VED, JIT, COVID-19.

\section{INTRODUCTION}

The main portion of assets and working capital in any sector is an inventory. Each organization needs a kind of inventory to be maintained for a smooth operation. Management of stocks ensures the availability and minimizes investment as required of materials. Inventory decisions include funding, promotion, sourcing and procurement management, which present high risks and have a direct financial effect on the organization. This study focuses on developing inventory management strategy in the pharmaceuticals. Management of stocks ensures the availability and minimizes investment as required of materials.

The pharmaceuticals in India has been closely monitored to analyze the impact of Covid-19 on its supply chain, mainly depending on China for the supply of some essential ingredients and intermediates. Currently, Covid-19 was responsible for many groundbreaking developments in material management in the pharmacies. There is lack of data on the spread of the Covid-19 and lack of visibility on the delivery of certain bulk medicines which leads to speculative increases in prices. In all the organizations, inventory from the financial and operational point of view is very important. There is therefore a need to determine stock quantity by inventory control as an integrated approach, so that costs to store and buy, become minimized without affecting any industry's functional efficiency, production, distribution etc.

This paper provides an overview of how pharmacists can use the following methods to improve current pandemic inventory management problems. Targeted inventory management techniques such as ABC, VED and VEN analysis carried out individually in different organizations are used to improve the efficiency of Pharmaceuticals. The $\mathrm{ABC}$ study helps to classify the elements that need to be monitored more closely. A mixture of ABC and VED (ABC - VED matrix) analysis can be used effectively to gain considerable control over medicinal supplies. Several other studies have shown that using these approaches for the wise use of drugs in day-to-day healthcare practices, inventory management strategies can contribute not only to significant clinical improvements, but also to the efficient use of medicinal resources.

\section{METHODOLOGY RESULTS \& ANALYSIS}

Literature review is typically time-consuming, as was also the case with Inventory Management in Pharmaceuticals, as related research articles have been scattered across different journals and conferences. We followed the 4-stage process of searching, collecting, sorting and selecting our papers.

\footnotetext{
> Stage 1: Search Strategy

The primary source for searching for our papers was through the use of the online resources of 'Google Scholar, Crossref and PubMed' as they are linked to large online databases of all major publishing journals, such as Springer, IEEE Xplore, Elsevier, Jyoung Pharma, NCBI and Science Direct, etc., to name a few. A variety of key terms were used to scan the possible literature, such as inventory
} 
management, inventory control techniques, pharmaceuticals, drugs etc.

\section{Stage 2: Identification of Papers}

The search and first pre-selection of papers was carried out at this stage and the scientific papers on the methods of inventory management used in pharmaceuticals were selected. In order to carry out a thorough and exhaustive search for literature, the keywords mentioned in stage 1 have been chosen, which are closely linked to our objective. Over 45 papers have been selected for the next phase, all collected papers have been stored and similar or duplicate papers have been deleted.

\section{$>$ Stage 3: Sorting and Classification of Papers}

Since the modernization of the inventory management system took place in the mid-1990s for the purposes of this review, the papers published after 1990 were taken into consideration from the papers collected during stage 2. At the end of this phase, only 30 papers were specifically selected for further review.

\section{$>$ Stage 4: Selection of Suitable Papers}

During this stage, 30 papers were examined in detail on the subject from which 20 relevant papers were selected and, our guide, whose expertise lies in the field of inventory management and operational research, independently reviewed the entire text of the published papers.

\section{RESULTS \& ANALYSIS}

The following accepted papers were initially examined and sorted on the basis of the field of study and the related factors addressed in those papers were selected on the basis of their outcomes.

\section{$>$ Konstantinos Danas, et al. $(2002)^{l}$}

This paper focuses on hospital pharmaceutical logistics operations and seeks to find a solution where these activities can be optimized. The authors suggest the concept of JustIn-Time and an information network that will replace hospital pharmacy with virtual pharmacy and distribute the actual stock of drugs in all hospital clinics in the same region. They propose that a stockless inventory system can be used to track, order and control the movement of drugs within the distribution chain through the Virtual Hospital Pharmacy (VHP) program and an integrated inventory management system. This can minimize or completely eliminate problems, such as out-of-stock and expired medicines, which significantly reduce the role of health care professionals who can focus on important research and not on inventory management. The authors also described inefficiencies and errors in the logistical operations of the hospital pharmacy and how VHP can help to resolve them.

\section{$>$ Lt Col R Gupta, et al. $(2007)^{2}$}

The focus of this paper was on how the ABC inventory control method is based on the cost factor and the VED method is based on the critical factor. Research was conducted at the 190-bed service hospital on the financial analysis of drug expenses in the priced vocabulary medical store (PVMS). The study shows that, For inventory management of drugs if they consider only the ABC analysis, they could control the recommended group A drugs, but would compromise the availability of vital drugs in categories $\mathrm{B}$ and $\mathrm{C}$. Likewise, the ABC-VED matrix shows that of the 292 items, 63 were Class 1, 164 were Class 2 and 65 were Class 3. Accordingly, the authors concluded that the cost factor was important for the optimal use of resources.

\section{$>$ R Nigah, et al. $(2010)^{3}$}

This research focuses on the analysis of VED and $\mathrm{ABC}$ in order to classify the types of items that need a rigorous management control, this analysis of pharmacy shop was performed in PGIMER. For each pharmacy item, annual use and expenses for 2007-2008 have been analyzed and also the stock control techniques, i.e. Analyzes of the matrix were made of VED, ABC and ABC-VED. These analyses classify medications requiring tight supervision over the effective use of funding with the reduction of down production in pharmacies. Such methods must be used as standard practice in order to maximize the use of resources and reduce non-restrictive situations in Pharmaceutical hospitals.

\section{Mahendrawathi ER, et al. $(2011)^{4}$}

This research proposes the use of the Fuzzy-ABC and combination of $\mathrm{ABC}$ and Fuzzy method for inventory management of pharmaceutical drugs in hospitals and to integrate various variables into an easily interpretable inventory management decision, but Prioritizing the items according to their importance was done by Analytical hierarchy method (AHP) it was applied to product classification, and data envelopment analysis (DEA) was proposed to maximize the artificial inventory but it should be reprogrammed whenever a new item is entered, therefore Fuzzy-ABC methodology was used to capture the intuition behind the value of pharmaceutical element to determine dollar usage and variables that are inexpressible.

\section{$>$ Jegadeesh Ramasamy D, et al. $(2012)^{5}$}

This research is focused on the analysis of inventory control of Drugs. The motive of this paper was to categorize the medicines according to costs and criticism and those that require strict management control are defined. The pharmaceutical medicines were categorized based on ABC and VED analysis, using an excellent spread sheet. This analysis allowed the classification of drugs on the basis of cost and criticism factors. This analyzes are aimed at promoting effective drug inventory management with minimum monetary resources, maintaining a high-priority drug safety requirement, and reducing drug supply shortages frequently. An effective inventory management program can lead to uncompromising patient care at primary health care.

\section{$>$ Kapoor, B, et al. $(2012)^{6}$}

The aim of this paper is to build and implement a modern outpatient pharmacy information system to help improve their pharmacy operations, which will address both the distribution and inventory features and significantly reduce product costs and improve service rates for its 
members through the Titan Healthcare JIT (Just-In-Time) method. As a result, Titan has implemented a JIT inventory management system to reduce safety stocks and improve supply reliability by reducing the Bullwhip Effect.

\section{Mahatme MS, et al. $(2012)^{7}$}

This paper examines the important role played by financial analysis in the management of a pharmaceutical store. The primary objective of this research was to consider the analysis of ABC-VED with EOQ, compare indexed costs with actual costs and forecast expenditure for future years. The authors concluded that the annual expenditure on medicinal products for the period 2010-11 accounted for $7,68 \%$ of the annual budget for hospitals. This percentage of ADE is lower than in previous studies. As a result, ABCVED optimizes the cost of Medicare services in collaboration with EOQ and applied economic analysis, as well as making money available to patients to improve the quality of health care.

\section{$>$ Manhas Anil K, et al. $(2012)^{8}$}

The objective of the study was to determine the cost and criticality of drugs stored in a pharmacy. The authors attempt to use the ABC analysis for the cost criteria, VED analysis for critical factor of the drugs. During this study period, a total of 156 products were tested for an inventory of medicinal products at SKIMS for a period of one year. The authors of the study expect the findings to help control the prices of medicinal products in pharmaceutical companies and to ensure that vital and essential drugs are accessible to patients and to hospital administration. They also suggested an analysis of the sales counter inventory, which includes more expensive drugs with far greater financial implications, and which may help in cost savings.

\section{$>$ Gustriansyah R, et al. $(2015)^{9}$}

The purpose of this paper is to establish a decisionmaking support system for pharmaceutical inventory management using approaches from FAHP, AHP and SPA. Hence To be more Efficient, DSS with FAHP and SPA methods are used to forecast inventory where the average percentage of accuracy exceeds the average percentage of the accuracy of the pharmacy inventory manager. Therefore, this method can be used as a method of decision-making support to enhance pharmacy inventory management.

\section{$>$ Sukhbir Singh, et al. $(2015)^{10}$}

The objective of this research is on the study of ABC and VED matrices in the Pharmaceutical Store, the teaching, testing, etc. which specifically needs precise management control. The goal of this analysis was to evaluate annual pharmaceutical use by using the priority model based on analysis of the ABC-VED matrix for the years 2008-2009 and 2009-20010. In order to identify categories of drugs which require striking controls on management, $\mathrm{ABC}$ and VED (in pharmacy/drug store) analysis were conducted in
PGIMER. It showed that for the effective use of available resources and the avoidance of non-hospital pharmacy circumstances, these technologies should be implemented. The analysis of ABC and VEDs could therefore be used to identify drugs that require stringent management control in order to use hospital funds effectively and efficiently.

\section{$>$ G. Santhi, et al. $(2016)^{11}$}

This study was aimed at ensuring that medicines are available when patients need them and to minimize the cost of medication by using inventory management by using ABC and VED analysis techniques. The RFID-based Pharmaceutical Inventory such as Blood Pharmacy, Control Techniques, and Hospital Inventory Management models were categorized and was analyzed to help patient's when they need. So, RFID tags were used to store appropriate quarantine material details. Therefore, A new model was developed by combining $\mathrm{ABC}$ and VED analysis called AVSER matrix. It gave the items in a community pharmacy with better priority management, thus making the process easy and efficient.

$>$ Migbaru, S. et al. $(2016)^{12}$

This study aimed at evaluating the flow of the Tikur Anbessa Advanced Hospital-TASH pharmaceutical inventory for the 2009-16 taxation years. The present investigation was a cross-sectional facility-based study in which the 5-year evaluation (2009-2013) was based on techniques of VEN, ABC with ABC/VEN analysis of this matrix. In five years -insulin, $\mathrm{NPH}$, test gloves, gauze bandage, chirurgical gloves and regular saline $1000 \mathrm{ml}$ existed with huge amounts of money. Many of the first category drugs in this sample were Cat-A and Class V drugs that require a great deal of attention for its supervision. The results of the study suggested that regular implementation of scientific tools for the management of pharmaceutical inventories, such as ABC-VEN matrix analysis, would be needed to improve the use of resources and the quality of patient care.

\section{Agada, P. O., et al. (2017) $)^{13}$}

Research in this paper focused on the quality of Central Pharmacy's health services at the Benue State University Teaching Hospital (BSUTH). The high demands of various pharmacies are constantly threatened by a Strong patient intake who require various care facilities. To solve the above-mentioned inventory problem there in, a prompt intervention is important as well as the tertiary health care system. This research was carried out by applying the Probabilistic EOQ model to the determination of the quantity of economic order (EOQ) and the degree of reorder for each consumable hospital and drug. The analysis of sensitivity results in a distribution of the response to each medication from EOQ as well as in a re-order degree of their respective cost adjustments. In this paper, this approach was suggested. 


\section{Z Zeynep CEYLAN, et al. $(2017)^{14}$}

The goal of this research was to control the product inventory of the pharmacy efficiently and to balance the drug rates, classify the economic and vital medication that is performed using $\mathrm{ABC}$ analysis, VED analysis and $\mathrm{ABC}$ VED analysis. The data have been reviewed in order to strictly control inventory and for optimal budget use. ABC analysis relies on the item's quality and rate of use; VED analysis classifies the medications according to their criticality and relevance to the patient's safety. Where VED analysis or $\mathrm{ABC}$ analysis is used alone, effective inventory management cannot be practiced. Therefore ABC-VED matrix in combination with $\mathrm{ABC}$ and VED was obtained. It offers tight control over the medications for optimum use in the budget.

\section{$>$ Ida Fitriana, et al. $(2018)^{15}$}

The focus of this paper was to analyze drug consumption goods and the costs of drug procurement, and to prioritize drug procurement processes based on traditional inventory techniques. Drug stock measurements have been troublesome. So, ABC analysis and VED analysis were the techniques used to solve the problem. The findings of this study showed that, for accurate and efficient monitoring of drug store scientific inventories, it requires the use of devices. Thus, based on the study of the matrix ABC, VED, and $\mathrm{ABC}-\mathrm{VED}$, it shows the drugs need strict regulation. Consequently, the ABC-VED approach should be implemented in the inventory of medicines under hospital drug control.

\section{Danyakam, S., et al. $(2018)^{16}$}

This research introduces an inventory management model aimed at improving successful medical inventory controls, thus increasing patient quality in the northeast of Thailand in the secondary hospital unit. It was proposed to identify and describe critics for the drug items being analyzed by the ABC-VED matrix analytical model. The study result from the model proposed showed that the highest expense of the overall expenditure was found in the critical and costly product category (category I). The exponential smoothing approach based on regression was also adopted to estimate the AE Subcategory I application and was calculated in terms of economic order quantity (EOQ) and the reorder point model. It can easily be taken into account to focus on key drug items and to reduce excessive drug inventory time and costs.

\section{> Faten Ben Chihaoui, et al. (2019) ${ }^{17}$}

The paper focuses on the Drug inventory management. The aim of this work was to optimize medical management by reducing drug inventory costs and improving patient satisfaction. The major issues in big inventory were Medicines scarcity, overstock, discrimination in the healthcare system, Unfunded technique of estimation, lack of knowledge. This research provides an actual case analysis of the same, the service indicated aims to automate the management and distribution of product stock while reducing drug shortages and production costs and 'The hybrid policy' was established. A DSS system was also implemented to help users improve the management of drug inventory and make reliable decision-making. This leads to better satisfaction for the patient.

\section{$>$ Hind, Abdelmonim Ahmed, et al. (2019) ${ }^{18}$}

The focus of this research is inventory management of Pharmaceuticals in Sudan central and hospitals which is done using ABC-VEN analysis. The data (NMSF \& RDF) have been reviewed using an excellent spread sheet in order to obtain information from the annual budget for $\mathrm{ABC}, \mathrm{VEN}$ and ABC-VEN matrix research and the control of pharmaceutical inventories. Sustainable Frameworks were used to assess knowledge of the inventory system amongst pharmacists employed at centers. Staff in drug treatment should be provided with extensive academic training and frequent workshops or seminars on the subject.

\section{$>$ Mansoor Hussain, et al. $(2019)^{19}$}

The primary aim of this paper was to establish an effective inventory management program that would help optimize resources and ultimately improve patient care through the use of inventory management strategies to minimize storage and internal lead times. The authors used $\mathrm{ABC}$ and VED methods to identify surgical consumables. The result of the study revealed that from $\mathrm{ABC}$ analysis 35, 52 and 171 items were categorized as A, B and C, respectively. The most important items in the VED analysis were $73 \%$ of the total items and $26 \%$ of all items were in the essential(e) category. The average lead time for internal, external and total periods was 17, 25 and 44 days, respectively.

\section{Taddele B. W, et al. $(2019)^{20}$}

The focus of the study was to assess the inventory of hospitals by means of an ABC-VEN matrix analysis and to identify drugs that require strict supervision. The study showed that Category I medicinal products require strict inventory controls and that Category II and Category III medicinal products require mid-and lower-level control, respectively The Research suggests that ABC-VEN techniques are to be implemented in a health care facility for the efficient use of resources and the disposal of waste. 


\section{SUMMARY OF LITERATURE REVIEW}

The techniques used for various inventory management problems are listed in table 1 below.

\begin{tabular}{|c|c|c|c|c|c|c|c|c|}
\hline \multirow[b]{2}{*}{ S1. No } & \multirow[b]{2}{*}{ Year } & \multirow[b]{2}{*}{ Authors } & \multicolumn{6}{|c|}{ Techniques (Check mark) } \\
\hline & & & $\mathrm{ABC}$ & VED & JIT & EOQ & DSS - FUZZY & VEN \\
\hline 1 & 2002 & Konstantinos Danas, et al. & $\square$ & $\square$ & $\checkmark$ & $\square$ & $\square$ & $\square$ \\
\hline 2 & 2007 & Lt Col R Gupta, et al. & $\checkmark$ & $\checkmark$ & $\square$ & $\square$ & $\square$ & $\square$ \\
\hline 3 & 2010 & R, Nigah, et al. & $\checkmark$ & $\checkmark$ & $\square$ & $\square$ & $\square$ & $\square$ \\
\hline 4 & 2011 & Mahendrawathi ER, et al. & $\checkmark$ & $\square$ & $\square$ & $\square$ & $\square$ & $\square$ \\
\hline 5 & 2012 & Jegadeesh Ramasamy D, et al. & $\checkmark$ & $\checkmark$ & $\square$ & $\square$ & $\square$ & $\square$ \\
\hline 6 & 2012 & Kapoor B, et al. & $\square$ & $\square$ & $\checkmark$ & $\square$ & $\square$ & $\square$ \\
\hline 7 & 2012 & Mahatme MS, et al. & $\checkmark$ & $\checkmark$ & $\square$ & $\checkmark$ & $\square$ & $\square$ \\
\hline 8 & 2012 & Manhas Anil K, et al. & $\checkmark$ & $\checkmark$ & $\square$ & $\square$ & $\square$ & $\square$ \\
\hline 9 & 2015 & Gustriansyah R, et al. & $\square$ & $\square$ & $\square$ & $\square$ & $\checkmark$ & $\square$ \\
\hline 10 & 2015 & Sukhbir Singh, et al. & $\checkmark$ & $\checkmark$ & $\square$ & $\square$ & $\square$ & $\square$ \\
\hline 11 & 2016 & G. Santhi, et al. & $\checkmark$ & $\checkmark$ & $\square$ & $\square$ & $\square$ & $\square$ \\
\hline 12 & 2016 & Migbaru, S. et al. & $\checkmark$ & $\square$ & $\square$ & $\square$ & $\square$ & $\checkmark$ \\
\hline 13 & 2017 & Agada, P. O., et al. & $\square$ & $\square$ & $\square$ & $\checkmark$ & $\square$ & $\square$ \\
\hline 14 & 2017 & Zeynep CEYLAN, et al. & $\checkmark$ & $\checkmark$ & $\square$ & $\square$ & $\square$ & $\square$ \\
\hline 15 & 2018 & Ida Fitriana, et al. & $\checkmark$ & $\checkmark$ & $\square$ & $\square$ & $\square$ & $\square$ \\
\hline 16 & 2018 & Kanyakam, S., et al. & $\checkmark$ & $\checkmark$ & $\square$ & $\checkmark$ & $\square$ & $\square$ \\
\hline 17 & 2019 & Faten Ben Chihaoui, et al. & $\square$ & $\square$ & $\square$ & $\square$ & $\checkmark$ & $\square$ \\
\hline 18 & 2019 & $\begin{array}{l}\text { Hind, Abdelmonim Ahmed, et } \\
\text { al. }\end{array}$ & $\checkmark$ & $\square$ & $\square$ & $\square$ & $\square$ & $\checkmark$ \\
\hline 19 & 2019 & Mansoor Hussain, et al. & $\checkmark$ & $\checkmark$ & $\square$ & $\square$ & $\square$ & $\square$ \\
\hline 20 & 2019 & Taddele B. W, et al. & $\checkmark$ & $\square$ & $\square$ & $\square$ & $\square$ & $\checkmark$ \\
\hline
\end{tabular}

Table 1

\section{CONCLUSION AND FUTURE SCOPE}

This study contains detailed information about current pharmaceutical inventory management practices. This document was written and developed by all of the authors involved, under the supervision of our guide.

In the course of this study, many various methodologies, i.e. ABC, VED, EOQ, JIT, etc. of Pharmaceutical Inventory Management have been individually analyzed and the findings suggest that, for optimal inventory management, if the above-mentioned methodological principles are implemented together in an automated environment such as VHP, which can help to keep stocks at an optimum level. While minimizing losses due to expired drugs and delays in ordering new stocks, we can minimize costs due to the low inventories (JIT) concept and the high availability of drugs based on their critical factor. Most researchers believe in the same ideas. The scope of this review in the future could help to explore the concept of the above model. Further, in order to monitor central pharmacy drugs, to make sure the budget is optimally allotted, and to prevent cases out of stock at the central pharmacy, suggestions are to be followed for hospitals in the categorization of drugs deriving from such research. In addition, emphasis should be placed on top administration for considering drugs pharmacies as an essential hospital facility and coordinating their activities to support them. The results of the analysis conducted in this research were found to be consistent and statistically significant with previous studies.

\section{REFERENCES}

[1]. Danas, K., Ketikidis, P., \& Roudsari, A. (2002). A virtual hospital pharmacy inventory: An approach to support unexpected demand. Journal of Medical Marketing, 2(2), 125-129.

[2]. Gupta, R. K. G. R., Gupta, K. K., Jain, B. R., \& Garg, R. K. (2007). ABC and VED analysis in medical stores inventory control. Medical Journal Armed Forces India, 63(4), 325-327. 
[3]. Nigah, R., Devnani, M., \& Gupta, A. K. (2010). ABC and VED analysis of the pharmacy store of a tertiary care teaching, research and referral healthcare institute of India. Journal of young pharmacists, 2(2), 201-205.

[4]. Mahendrawathi, E. R., Laili, E. N., \& Kusumawardani, R. P. (2011, December). Classification of hospital pharmaceutical drug inventory items by combining $\mathrm{ABC}$ analysis and fuzzy classification. In 2011 International Conference on Advanced Computer Science and Information Systems (pp. 215-220). IEEE.

[5]. Ramasamy D, J. et al. (2012). Drug Inventory control analysis in a Primary level Health care facility in Rural Tamil Nadu, India. age, 3, 6.

[6]. Kapoor, B., \& Mullen, T. (2012). Integration of Just In Time (JIT) Inventory in Outpatient Pharmacy Information Systems. Journal of Cases on Information Technology (JCIT), 14(4), 27-40.

[7]. Mahatme, M. S., Hiware, S. K., Shinde, A. T., Salve, A. M., \& Dakhale, G. N. (2012). Medical store management: An integrated economic analysis of a Tertiary Care Hospital in Central India. Journal of Young Pharmacists, 4(2), 114-118.

[8]. Manhas Anil, K., Aubid, M., Haroon Rashid, S. M. A., \& Syed, A. T. (2012). Analysis of inventory of drug and pharmacy department of a tertiary care hospital. Analysis, 25(3), 183.

[9]. Gustriansyah, R., Sensuse, D. I., \& Ramadhan, A. (2015, November). Decision support system for inventory management in pharmacy using fuzzy analytic hierarchy process and sequential pattern analysis approach. In 2015 3rd International Conference on New Media (CONMEDIA) (pp. 1-6). IEEE.

[10]. Singh, S., Gupta, A. K., \& Devnani, M. (2015). ABC and VED analysis of the pharmacy store of a tertiary care, Academic Institute of the Northern India to identify the categories of drugs needing strict management control. Journal of young pharmacists, 7(2), 76.

[11]. Santhi, G., \& Karthikeyan, K. (2016). Recent review article on pharmaceutical inventory models. International Journal of Pharm Tech Research, 9(5), 435-443.

[12]. Migbaru, S., Yigeremu, M., Woldegerima, B., \& Shibeshi, W. (2016). ABCVEN matrix analysis of pharmaceutical inventory management in tikur anbessa specialized hospital for the years 2009 to 2013, addis ababa, ethiopia. Indian J. Basic Appl. Med. Res, 5, 734-743.

[13]. Agada, P. O., \& Ogwuche, E. H. (2017). A Probabilistic Economic Order Quantity (EOQ) Model for Inventory Management Of Drugs And Hospital Consumables. Department of Mathematics/Statistics/Computer Science Journal.

[14]. CEYLAN, Z., \& BULKAN, S. (2017). Drug inventory management of a pharmacy using $\mathrm{ABC}$ and VED analysis. Eurasian Journal of Health Technology Assessment, 2(1), 14-18.

[15]. Fitriana, I., Satria, R. G. D., \& Setiawan, D. C. B. (2018). Medicine Inventory Management by ABC-
VED Analysis in the Pharmacy Store of Veterinary Hospital, Yogyakarta, Indonesia. Asian Journal of Animal and Veterinary Advances, 13(1), 85-90.

[16]. Kanyakam, S., Pimpa, W., \& Kamlai, K. (2018). Inventory Management in Medical Stores of Secondary Care Unit Service Level Hospitals in Northeast of Thailand. Mahasarakham International Journal of Engineering Technology, 4(1), 17-23.

[17]. Chihaoui, F. B., Maddeh, N., Layeb, S. B., Hamouda, C., \& Chaouachi, J. (2019, April). A Decision Support System for Drug Inventory Management within an Emergency Department: A Case Study. In 2019 6th International Conference on Control, Decision and Information Technologies (CoDIT) (pp. 1889-1894). IEEE.

[18]. Ahmed, H. A., Kheder, S. I., \& Awad, M. M. Pharmaceutical inventory control in Sudan central and hospital stores using ABC-VEN analysis.

[19]. Hussain, M., Siddharth, V., \& Arya, S. (2019). ABC, VED and lead time analysis in the surgical store of a public sector tertiary care hospital in Delhi. Indian journal of public health, 63(3), 194.

[20]. Taddele, B. W., Wondimagegn, A. A., Asaro, M. A., Sorato, M. M., Gedayi, B. G., \& Hailesilase, A. A. (2019). ABC-VEN matrix analysis of the pharmacy store in a secondary level health care facility in Arbaminch Town, Southern Ethiopia. Journal of Young Pharmacists, 11(2), 182. 